\title{
The impact of business analytics on supply chain performance
}

\author{
Peter Trkman ${ }^{\mathrm{a}, *}$, Kevin McCormack ${ }^{\mathrm{b}}$, Marcos Paulo Valadares de Oliveira ${ }^{\mathrm{c}, \mathrm{d}, \mathrm{e}}$, Marcelo Bronzo Ladeira ${ }^{\mathrm{c}}$ \\ a University of Ljubljana, Faculty of Economics, Kardeljeva ploscad 17, 1000 Ljubljana, Slovenia \\ b DRK Research, USA \\ c Universidade Federal de Minas Gerais, Brazil \\ d Fundação Dom Cabral, Brazil \\ e Centro Universitário UNA, Brazil
}

\section{A R T I C L E I N F O}

\section{Article history:}

Received 17 September 2009

Received in revised form 14 February 2010

Accepted 28 March 2010

Available online $\mathrm{xxxx}$

\section{Keywords:}

Supply chain management

Analytical capabilities

Information systems

Business process management

Performance

SCOR

\begin{abstract}
A B S T R A C T
The paper investigates the relationship between analytical capabilities in the plan, source, make and deliver area of the supply chain and its performance using information system support and business process orientation as moderators. Structural equation modeling employs a sample of 310 companies from different industries from the USA, Europe, Canada, Brazil and China. The findings suggest the existence of a statistically significant relationship between analytical capabilities and performance. The moderation effect of information systems support is considerably stronger than the effect of business process orientation. The results provide a better understanding of the areas where the impact of business analytics may be the strongest.
\end{abstract}

(c) 2010 Elsevier B.V. All rights reserved.

\section{Introduction}

In the modern world competition is no longer between organizations, but among supply chains ('SCs'). Effective supply chain management ('SCM') has therefore become a potentially valuable way of securing a competitive advantage and improving organizational performance $[47,79]$. However, the understanding of the why and how SCM affects firm performance, which areas are especially important and which are the important moderator effects is still incomplete. This paper thus analyses the impact of business analytics ('BA') in a SC on the improvement of SC performance.

The topic is important since enhancing the effectiveness and efficiency of SC analytics is a critical component of a chain's ability to achieve its competitive advantage [68]. BA have been identified as an important "tool" for SCM [44] and optimization techniques have become an integral part of organizational business processes [80]. A correct relevant business decision based on bundles of very large volumes of both internal and external data is only possible with BA [68]. It is therefore not surprising that research interest in BA use has been increasing [43].

However, despite certain anecdotic evidence (see for instance the examples given in [19]) or optimistic reports of return-on-investment exceeding $100 \%$ (see e.g. [25]) a systematic and structured analysis of

\footnotetext{
* Corresponding author. Tel.: +386 15892 512; fax: +386 15892698. E-mail address: peter.trkman@ef.uni-lj.si (P. Trkman).
}

the impact of BA use on SC performance has not yet been conducted. Accordingly, the main contribution of our paper is its analysis of the impact of the use of BA in different areas of the SC (based on the Supply Chain Operations Reference ('SCOR') model) on the performance of the chain. Further, the mediating effects of two important constructs, namely information systems ('IS') support and business processes orientation ('BPO'), are examined.

The structure of the paper is as follows: first, the importance of BA and its potential influence on the SC is established. The moderating effects of both BPO and IS support are discussed. The research model is presented. Then the methodology (including the sample and questionnaire) and results obtained are presented. The conclusion discusses the main implications for research and practice and outlines the limitations of our research and potentially interesting topics for further research.

\section{Theoretical background}

BA are defined for the purpose of this paper as an application of various advanced analytic techniques to data to answer questions or solve problems related to SCM. BA are not a technology but a group of approaches, organizational procedures and tools used in combination with one another to gain information, analyze that information, and predict outcomes of problem solutions in any of the four areas of SCOR (Plan, Source, Make, and Deliver) (definition adapted from [9]).

It has previously been well established that the adoption of SCM systems can lead to better financial performance through an 
improvement in inventory turnover and reduction of sales expenditure. Additional advantages in the SC can also be realized [21]. Yet, on the other hand, despite major investments in SCM systems in the last decade those systems are often struggling to achieve a competitive advantage [68]. Even worse there is a complete absence of a specific and rigorous method to measure their realized business value [24]. Further, papers have focused on companies' initial experiences and not on improvements over time [84]. This leaves a strong need to study the impact of BA, the factors that influence this impact and the areas of SCM with the largest effect on it. Our paper contributes to this area with its analysis of the impact of BA in various areas of the SC and the moderating effects of this impact.

The paper's contribution can be framed within the information processing theory that stipulates that the linkage between a key organizational resource (information) and its management (i.e., the use of information) is an organization's most critical performance factor $[27,36]$. Exploiting information to improve processes and/or outcomes is the focus of most activities in SCM [42] and effective SC practices can increase information processing capacity [85]. The information processing and knowledge development process is thus an important antecedent to SC efficiency [42].

In our case the information acquired in four SCOR areas is examined, while the management of information is affected by BPO and IS support which are considered as moderating effects in the paper.

\subsection{The influence of $B A$ on performance}

Monitoring and improving the performance of a SC has become an increasingly complex task and includes many management processes such as identifying measures, defining targets, planning, communication, monitoring, reporting and feedback [12]. Thus an approach relying on conventional wisdom to making SC-connected decisions, the use of benchmark or best-practices etc. cannot be used to manage the SCs.

Therefore, data analysis lies at the heart of decision-making in all business applications [11]. The same applies to the SC context as a correct relevant business decision based on bundles of very large volumes of both internal and external data that is only possible with BA that enable the analysis of data gathered in vast quantities on a regular basis [3,68]. For example, a typical supplier evaluation framework (e.g. [78]) requires the inclusion of several variables for each supplier in the calculation of a supplier performance score. Since a large company may have thousands of different suppliers, the use of such frameworks is impossible without BA.

BA are being increasingly used in SCM. Improving SC performance has become a continuous process that requires an analytical performance measurement system [12]. Moreover, the use of BA aids a knowledge enterprise by promoting efficiency within an organization, particularly by using analytical methods to provide valuable decision-making knowledge to minimize operating costs and accurately forecast market trends [34]. Companies with more mature SC practices, i.e. improved BA capabilities, are thus reducing their costs faster and achieving higher profit margins than their less mature peers [38]. Moreover, higher levels of SCM practice such as a higher level and quality of information sharing can lead to an enhanced competitive advantage and improved performance [47].

Due to this complexity SCs often turns to software to streamline and standardize operations. The implementation of a decision support system can provide a distinct competitive advantage. However, careful implementation is needed to fully realize the potential of such a system [70]. The success of such IT investment is thus not self-assured; the main challenge is how to best utilize the data provided by the software. Many organizations that already have systems in place to collect data and gather information often find themselves in a situation where they do not have a suitable approach to put their vast data and information into use for strategic decisionmaking [63]. It is also critical that the organization constantly evaluate its models to ensure their predictive validity. Updating the models when necessary provides profound knowledge about the changes in the underlying conditions that affect the performance [17].

\subsection{The ways BA influence performance}

As shown, the potential positive impact of BA on SC performance is well established; however, the potential ways and moderating influences of this impact are not so well understood. Most previous research papers have used SCM as an umbrella term to analyze this impact. Yet it should not be forgotten that SCM is quite a broad term and encompasses the integration of organizational units and business processes along a SC to coordinate materials, information and financial flows in order to fulfill customer demands [73]. SCM is therefore still largely eclectic with little consensus on its conceptualization [10] and can basically encompass every business activity in a company. In this sense, a more precise reference is needed to analyze the impact of BA.

Since SCOR has been widely employed for SC optimization in recent years (see e.g. $[7,12,41]$ ), it was used as a framework for our study. SCOR has often been recognized as a systematic approach to identifying, evaluating and monitoring supply chain performance $[12,50]$. In the SCOR model, a balanced performance measurement system at multiple levels, covering four core SC processes (Plan, Source, Make, Deliver, and later Return was also added), was developed [12]. SCOR is supposed to be the most promising model for SC strategic decision-making [41]. It provides a common SC framework, standard terminology and metrics that can be used for evaluating, positioning and implementing SC processes [41]. The choice of SCOR also reflects the fact that SC analytics include planning, sourcing, making and delivery [68] which corresponds to the SCOR areas.

Examples of the potential use of analytics in various areas include:

- in Plan: analyzing data to predict market trends of products and services; until recently, these have often been done in the form of monthly and yearly reports by marketing and finance departments [3];

- in Source: the use of an agent-based procurement system with a procurement model, search, negotiation and evaluation agents to improve supplier selection, price negotiation and supplier evaluation [46] and the approach for supplier selection/evaluation [78];

- in Make: the correct production of each inventory item not only in terms of time, but also about each production belt and batch [63]; and

- in Deliver: various applications of BA in logistics management have been made in order to bring products to market more efficiently [65]. Nevertheless, since decisions about delivery are usually at the end of the decision cycle and several companies have outsourced their delivery processes the impact of BA in delivery may be limited.

Several similar examples of BA use in various areas were previously reported. In general, improvements in any of the four areas can considerably increase the SC performance [50]. However, the influence of BA in each of these four areas has not been analyzed and its impact remains to be measured.

The positive impact of BA is however not self-assured but has to be moderated by IS support and possibly also by the BPO. Modern BA tools have namely not only been successfully incorporated into existing organizational ISs but have also become an integral part of organizational business processes [80]. Unless data collection is automated, it is difficult to institutionalize the SCOR model as a measurement and benchmarking framework [33]. The link between IT use and the simultaneous design of business processes is a vital 
ingredient to bring a benefit from such development efforts. In fact, in practice it is often difficult to separate the origin of the benefit, whether it has derived from IT, a process change, or both [2].

This is understandable since organizations interact on a real-time basis and business processes cut across multiple departments and business lines [69]. The Internet has enabled the adoption of a new generation of processes based on Internet technology that allows them to improve the performance of their cross-organizational processes with customers, suppliers and partners [58].

Although both effects are obviously connected, it may still be important to identify which are the moderating effects of each of them separately. Therefore, each of the moderating effects is discussed separately in the next sections.

\subsection{The moderating effect of the business process orientation}

Business process redesign projects can improve business processes, increase the business process orientation ('BPO') and improve efficiency/business performance (see e.g. $[31,32,51,56,77]$ ). However, the concerted effort of users and/or consultants can only bring a chain to a certain point since most process owners have limited information about what is actually happening [72] and analyses are usually separated in dispersed domains without an overview of their effectiveness [19].

As shown, BA is gaining an importance but the main question remains: what to optimize and how to help decision-makers in organizations harness the vast quantity of data available in SCM software [70]? Often companies do not use the information gained to fine-tune the day-to-day operations of their business processes and merely collect it in business data warehouses for later use [37].

This poses the question of how to assure that BA will indeed be used to improve the operation of a SC. Our hypothesis is that the BPO [52] has a moderating effect between BA use and SC performance. Therefore, both BPO and BA maturity have to increase in order to lead to improved business performance. This could mean that companies that are more process-oriented are in a better position to utilize BA to improve their performance. This is in line with the previous finding that BA systems have to be process-oriented to link across functions/ break the functional perspective at both the strategic and tactical levels $[60,65]$.

The business process redesign and inclusion of inter-organizational business processes is needed in order to exploit the advantages of factbased strategic SC planning [71]. Executives must thoroughly analyze which key business processes to integrate and manage [45]; integrating business processes is namely a best practice in SCM and involves coordinating decisions across multiple facilities and tiers [57].

This is in line with information processing theory since business processes should be designed to minimize the computation, acquisition and communication costs [62], thus improving information processing capabilities. Information processing aspects of business processes may create environments for the effective storage and sharing of the data and results obtained by BA [62]. However, in order to enable an increase in information processing capabilities difficult and painful organizational changes may be needed to enable fact-based planning and decision making [71].

Several reasons make BPO especially important. Since most firms offer similar products and use comparable technologies, business processes are among the last remaining points of differentiation with BA optimizing their value [19]. In the long-term, BA techniques and findings will be imbedded into business processes [59]. However, currently few of the new process mining techniques have been tested on real-life processes [81]. With collaborative business processes and the seamless integration of processes of different organizations, dynamic and flexible collaborations can be created in order to improve performance [48].
Further, in order to fully use BA companies need to undergo thorough business process changes, apply change management practices and focus on changing downstream decision-making and business processes [82]. Only when users become aware of these possibilities can they leverage data for business process improvement [84]. Further, managers should guide the process of cultural change so the use of business information, BA and fact-based decision-making becomes ingrained in the way the business operates and thus greater BA maturity can be achieved $[60,83]$. When this process is faulty, the result is the common phenomenon of paralysis by analysis [25].

This increase in the BPO should encompass both the internal and external integration of business processes: the internal integration can be one of the prerequisites for the use of BA in external business processes. Today, few organizations have achieved complete internal integration [5]. In fact, the level to which the SC integrates internal and external business processes can be one of the main determinants of the success of such initiatives [37]. Thus a proper level of maturity of business processes (see e.g. [52,56]) may be needed.

\subsection{The moderating effect of IS support}

IS is an integrated set of components for collecting, storing, processing, and communicating information [26]. BA use a large database as the source of information and as the basis for sophisticated analysis. BA emphasize the analysis of large volumes of data about the firm and its operations [59]. Therefore, IS has a fundamental role in enabling organizations to develop new capabilities and skills that would otherwise be impossible to accomplish [8]. In line with the information processing view, IS can increase the overall information processing capacity of a firm. Firms with superior IS capabilities are better able to collect, process and assimilate complex external information and formulate an effective response [11,18]. IS matters because it importantly affects the organizational dynamic capabilities [4], thereby also its information processing capabilities.

Yet, contrary to these findings, firms utilizing the most recent technological inputs have market returns significantly below the mean [35] and the IS investment per se will not bring a competitive advantage $[13,14]$. Thus it seems that IS will play a moderating role on the impact of BA on SC performance. The proposed moderating effect is in line with the finding that IS investment influences performance through IS support for core competencies [64], in our case competencies in each of the four areas of SCOR.

Obviously this shows that IS per se does not necessarily bring those advantages since BA are also about culture, people's views of the value of information, exploratory and predictive models and fact-based management [40]. However, the ability to sense and interpret events about a changing business environment or customer needs require an eventdriven IS infrastructure for making fast and well-informed decisions and putting them into action [69]. IS namely plays an enabling role in collaboration practices and the capabilities and sophistication of the underlying IS infrastructure supports various ways of collaboration [61] both within the company and at the inter-organizational level. On the other hand, the technical uncertainty on reliability and complexity of integrating internal ISs can also be a hindering factor [61].

Nevertheless, IS may have an additional independent influence on SC performance. All organizations namely benefit from using IS to increase their cost-effectiveness. However, advanced uses of IS should be more closely aligned with an organization's strategy [27]. It is also possible to initially build the infrastructure and to then decide on when and how much additional commitment should be made to build on top of that $[6,22,23]$; in our case, proper IS support can be developed earlier and later used to support the implementation of BA.

The definition and the questions in the survey are intentionally quite broad in order to measure the (perceived) support of IS. As found by [30], the value of a technology depends upon the tasks of the 
user. User evaluations can therefore accurately reflect differences in the underlying systems and services provided to them. The employed technological solution (e.g. extended ERP system, web services) may vary from company to company.

\section{The research model}

The research model in Fig. 1 was used to analyze the relationships between BA in SCM and the performance in the SCOR areas of Plan, Supply, Make, and Deliver, considering IS support and the business process orientation as moderators of this relationship.

The moderator constructs Process Orientation and Information Systems Support affect the correlations between analytics and SC performance without necessarily being directly correlated with any of those constructs $[1,39]$.

\subsection{Methodology}

This present study assumes both a descriptive and exploratory character since it aims to describe and organize information about the influence of analytics, BPO and IS support on SC performance.

This research builds upon earlier research that gathered global data on SCM maturity [49]. The survey included questions about the key SC decision practices and their level of use in the supply chain. A literature review, along with discussions and interviews with supply chain experts and practitioners, were used in the original research project as the basis for developing the survey questions. The discussions and interviews were structured around the SCOR Model. The experts and practitioners used in developing and validating the original measures were selected from the Supply Chain Council's member list. This list spanned multiple industries and contained individuals working within the SC domain.

For this research, specific measures representing only analytics practices within each SCOR decision area were identified and validated by building a candidate list of analytics practices and circulating the list among SCM experts, asking them to accept or reject the measure as representing a BA practice.

The SC performance construct is a self-assessed performance rating for each of the SCOR decision areas. The construct is based on perceived performance, as determined by the survey respondents. It is represented as a single item for each decision area. The specific item statement on the supply chain performance for each of the SCOR decision areas is: "Overall, this decision process area performs very well." The participants were asked to either agree or disagree with the item statement using a five-point Likert scale ( $1=$ strongly disagree; $5=$ strongly agree)

We measured the general process orientation of the organization (level of definition, culture, and horizontal structure) using measures developed in earlier research rather than any specific BPM approaches or activities. Further, BPM is a relatively broad term [77] and can be perceived differently by different respondents. On the other hand, BPO and its measurement were well tested in earlier research [53]. The measures evaluated the level of process definition and documentation, the functional or process orientation of the organizational structure, performance measures, people and jobs in the supply chain organization. These measures were considered as formative variables to compose the construct of business process orientation.

The Information Systems Support construct was represented by self-assessment measures directly asking whether the "information systems currently support" the overall supply chain processes, the order commitment process, distribution management, the Make process, the Source process and the demand management process. These measures were considered as formative variables to compose the construct of Information Systems Support. The definition and the questions concerning Information Systems Support were intentionally quite broad in order to measure the (perceived) support of IS. This approach has been shown to measure the end user perspective of IS support within a process context [50]. The value of a technology namely depends upon the tasks of the user. User evaluations can therefore accurately reflect differences in the underlying systems and services provided to them [29]. A vast majority of survey participants were business users of technology and they seem to generalize all technologies as IS support.

\subsection{Data collection}

The survey instrument was developed using a 5-pointLikert scale measuring the frequency of practices consisting of: 1 - never, or does not exist; 2 - sometimes; 3 - frequently; 4 - mostly; and 5 - always, or definitely exists. The initial survey was tested within a major electronic equipment manufacturer and with several SC experts. Based upon these tests, improvements in wording and format were made to the instrument and several items were eliminated.

The Supply Chain Council board of directors also reviewed the initial survey instrument. Based on this review, the survey was slightly reorganized to better match the SCOR model. The survey

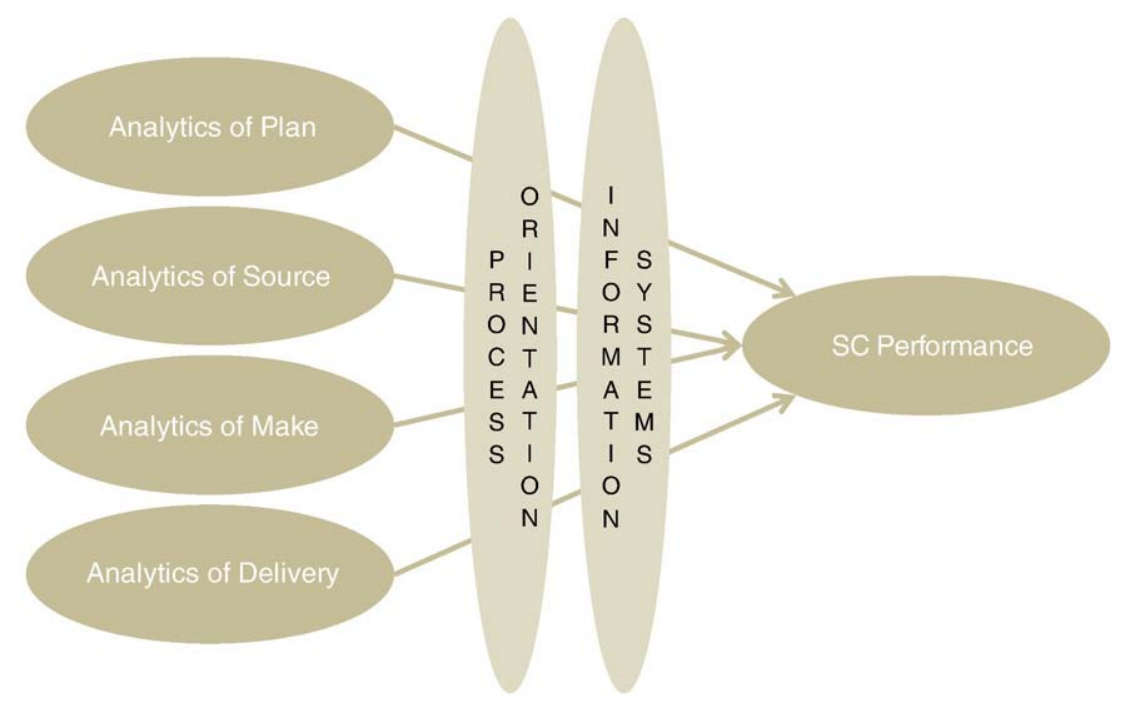

Fig. 1. Nomothetical research model. 
questions grouped by SCOR decision area are provided in Appendix A. The questions focus on decision-making in the key SCM decision categories for each of the four SCOR decision areas.

\subsection{Sample}

The final sample was composed of respondents whose functions are directly related to SCM processes from 310 different companies with headquarters in the USA, Europe, Canada, Brazil and China. The dataset used was made up of cases collected from research on the SCMMM - Supply Chain Management Maturity Model [55]. The sample deliberately included companies from different industries since various industry settings need to be investigated in the context of global supply chains [57].

The study participants were selected from several sources:

1. The membership list of the Supply Chain Council. The "user" or practitioner portion of the list was used as the final selection since this represented members whose firms supplied a product, rather than a service, and were thought to be generally representative of supply chain practitioners rather than consultants.

2. Firms that were interested in measuring their supply chain maturity and developing an improvement plan. These firms responded to an email solicitation recruiting participants for a global research project on Supply Chain Maturity.

3. Companies formally associated with IMAM. IMAM is a recognized logistics education and consultancy institution in São Paulo, Brazil. By accessing the mailing list of this institution, the sample composition evolved: manufacturing firms; construction firms; retail businesses; graphic industries; extractive firms; communication and IT providers; and gas, water and electricity productive facilities and distribution services.

A combined sample profile is provided in Fig. 2. The respondents came from nine positions (sales, IS, planning and scheduling, marketing, manufacturing, engineering, finance, distribution, and purchasing). Approximately $20 \%$ of the respondents work in other positions mainly in new supply chain oriented jobs such as "Global Supply Chain Manager" or "Supply Chain Team Member". A profile of the respondents by position is provided in Fig. 3. The share of senior leaders/executives, managers and consultants/individual contributors is approximately the same.

$49 \%$ of the companies came from the manufacturing industry, $18.9 \%$ from logistics and communication services, $7.2 \%$ from the food

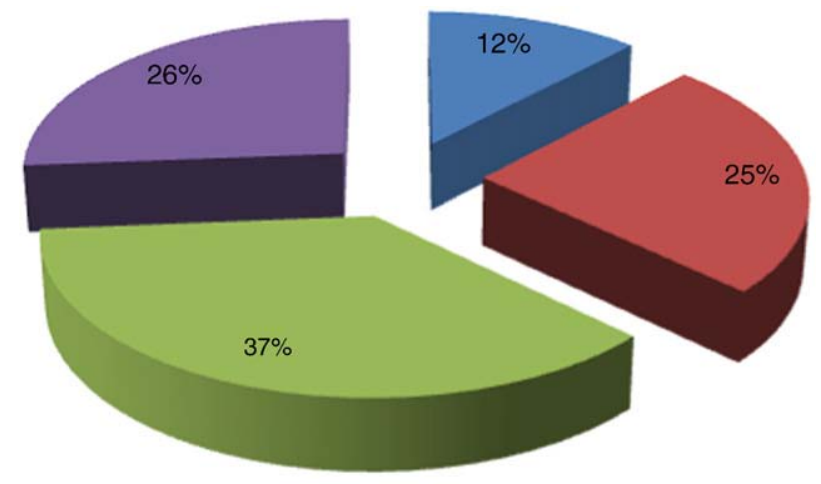

$\begin{array}{lll}\text { Sr. Leadership/Executive } & \text { Sr. Manager } \\ \text { Manager } & \text { Individual Contributor }\end{array}$

Fig. 3. Participants by respondent position.

industry, 5.2\% from the auto industry and home utilities and 19.3\% from other industries.

\subsection{Data analysis}

Structural equation modeling (Partial Least Squares; PLS) was used to test the hypothetical model and evaluate the influence of the moderators over the variables.

Initially the constructs of analytics capabilities in the Plan, Source, Make and Delivery areas of SCOR were considered as latent variables of the formative construct related with performance. The $R^{2}$ coefficient is 0.667 , which demonstrates that the indicators of analytical capabilities were able to explain $66.7 \%$ of the variability in the performance results.

Afterwards the constructs of "Business Process Orientation" and "Information System Support" were added to the former model as independent and exogenous variables. The results showed a $R^{2}$ of 0.6925 , revealing that the analytical capabilities indicators jointly with those two new constructs explained $69.25 \%$ of the variability in the results of the performance of the companies in the sample.

In the last stage the constructs of "Business Process Orientation" and "Information System Support" were considered as moderators

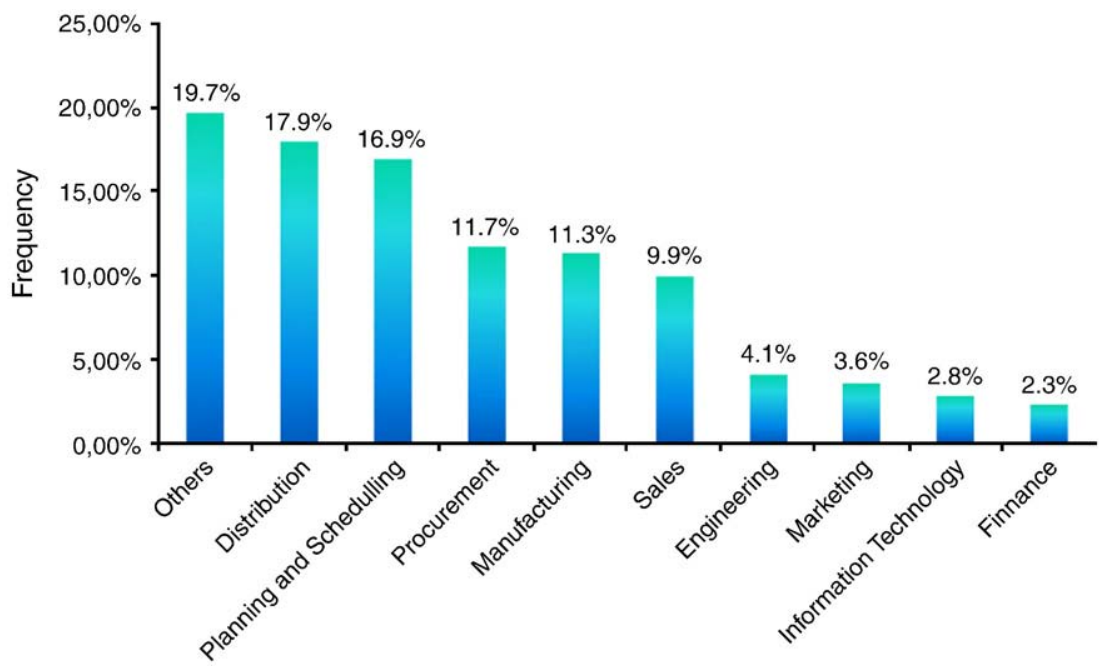

Fig. 2. Participants by industry. 
Table 1

Overall results and cutting values.

\begin{tabular}{lll}
\hline Indicator & Performance & Cutting values \\
\hline AVE & 0.5751 & $>0.5$ \\
Composed reliability & 0.8434 & $>0.8$ \\
$R^{2}$ & 0.7231 & $>0.67$ \\
Cronbach's alpha & 0.752 & $>0.6$ \\
Communality & 0.5751 & - \\
Redundancy & 0.0556 & - \\
\hline
\end{tabular}

of the relationships. The results presented an even greater $R^{2}$ of 0.7231 . The overall results of the structural equation modeling considering the moderators are summarized in Table 1 indicating the respective cutting values used for evaluating the model as proposed by [28].

The results obtained demonstrate that the scales used to measure the constructs should be considered as acceptable. As an alternative to the Cronbach alpha, considering that it can underestimate the scale reliability, the composed reliability was calculated and showed a high value that is valid for confirmatory purposes. The AVE - average variance extracted - reflects the average communality for each formative latent factor. A value greater than 0.5 proves the model convergence is valid [28].

Communality represents the sum of the correlations at the reflexive block with the formative latent variable. High indicators of communality indicate a variable that fits well to the solution [75]. It measures the percentage of variance from one variable that can be explained by all the remaining factors together. The impact of the remaining factors should also be considered; a communality of 0.25 can look quite low but can be significant if the item is important to improve the definition of the model. In the same way, the redundancy score measures the quality of the structural model for each endogenous block, considering the measurement model. Redundancy measures the percentage of the variance in the factor that can be explained by the remaining indicators, exogenous factors of the model [28].

Finally, the criterion of global fitness (GoF) [75] was calculated. The GoF is a geometric average of all communalities and $R^{2}$ in the model. The GoF is an index that can be used to validate models with PLS. In our case:

GoF $=\sqrt{\overline{\text { communality }} * \overline{R^{2}}}=0.56$.
This shows that the model is ready to consider $56 \%$ of the reachable fitness. A value higher than the cutting point of 0.5 shows that the set of structural equations is well defined, offers a good representation of the dataset and is valid with a "moderate» fitness [66].

In addition, the structural equation modeling brought an estimative of the total effects of the model variables over the performance results. Those results are graphically presented in Fig. 4 below, regarding the nomothetical model developed in this research.

In order to test the structural components of the model, the Bootstrapping alternative was used to randomly generate 310 new additional samples based on the proposed model (each sample sizing 310 cases) and, further, the Jacknife method was used to test each construct of the model. The results (Table 2) show a $p$-value for each link.

All structural model relationships were validated considering a cutting $p$-value of 0.05 . This shows that our model has excellent scores of adjustment revealing strong evidence that companies aiming to adopt IS to support their analytical capabilities tend to achieve a better SC performance.

On other hand, it is questionable that more process-oriented companies will tend to achieve a better SC performance. Research results indicate that while a BPO has the statistically validated moderator effect being considered, it was relatively weak. It can be argued that the BPO can be beneficial in supporting BA and improving performance. However, those companies that are functionally oriented can also take advantage of BA when strong IS support is in place.

Fig. 2 shows that the analytics of Make have the biggest influence on SC performance. This shows that investment in this area (e.g. implementing practices of sales and operations planning; inserting data from customers' systems into the internal production plan; and detailing the production plans for each item) can greatly affect the SC performance.

\section{Discussion and conclusion}

The research results show that the use of BA in critical process areas can affect a SC's performance. These findings were confirmed on a large sample of companies from different industries and countries. Our results reinforce the importance of a company's use of its databases, explicative and predictive models and fact-based management to drive its decisions and actions. The analytical capabilities can better guide the exclusively human decisions and provide automated decisions in some tasks in organizations.

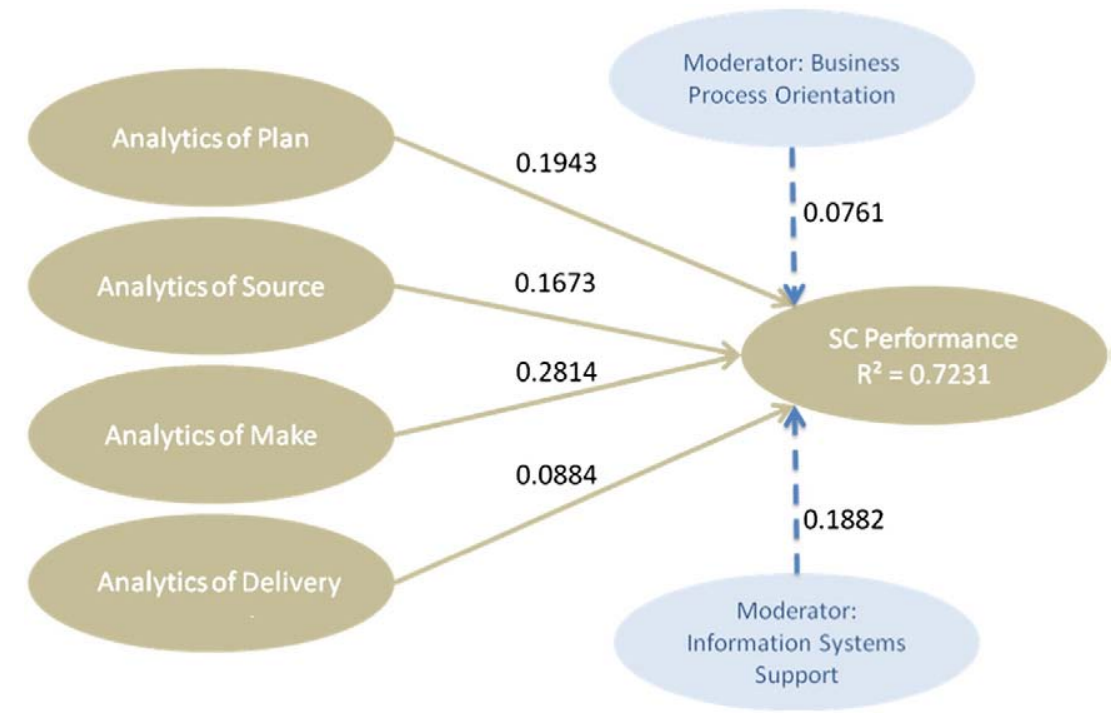

Fig. 4. PLS results for the model with the effects of the moderators. 
Table 2

Test of the total effects using bootstrapping.

\begin{tabular}{|c|c|c|c|c|c|c|}
\hline Relationships & Original sample & Bootstrapping mean & Std. deviation & Std. error & $T$-statistics & $p$-value \\
\hline Make to performance & 0.281 & 0.263 & 0.047 & 0.047 & 5.968 & $6.562 \mathrm{E}-09$ \\
\hline Plan to performance & 0.194 & 0.206 & 0.049 & 0.049 & 4.003 & $7.847 \mathrm{E}-05$ \\
\hline Source to performance & 0.167 & 0.162 & 0.038 & 0.038 & 4.353 & $1.827 \mathrm{E}-05$ \\
\hline Delivery to performance & 0.088 & 0.098 & 0.045 & 0.045 & 1.980 & 0.0485 \\
\hline IS support as moderator & 0.188 & 0.194 & 0.043 & 0.043 & 4.412 & $1.415 \mathrm{E}-05$ \\
\hline $\mathrm{BPO}$ as moderator & 0.076 & 0.079 & 0.038 & 0.038 & 2.007 & 0.0456 \\
\hline
\end{tabular}

In addition, companies that support their analytical capabilities with good IS are likely to be more capable of performing better. Interestingly, the results provide limited support for the impact of analytics in the delivery area and the moderating effect of a business process orientation. The former is possibly due to the fact that delivery is often outsourced and decisions take place at the end of the decision process where their effect may be limited. Another possible explanation is the finding in [15] that marketing/logistics collaboration does not have a direct impact on firm performance but increases firm performance through the mediation of firm-wide cross-functional integration. Finally, companies may not yet be sufficiently advanced in their use of BA enough; possibly the use of BA in the Deliver area has a greater impact on performance after a certain level has been reached in other three areas (Plan, Source, and Make).

The results might have differed had the sample mainly included ebusiness SCs (e.g. online retailers) where the effect of delivery on performance may be stronger (see e.g. [16]). Further, the impact of BA in delivery could be stronger if risks (see e.g. $[67,78]$ for a review of SC-connected risks that often arise in a delivery area) and not only performance had been considered since BA analytics in delivery may be largely focused on risk prevention.

However, the paper did not provide strong support for the moderating effect of a BPO. It is possible though that the sample included relatively process-mature companies or that companies have increased their BPO as a side-effect of the focus on BA; the lack of a BPO may be a limiting factor at lower levels of maturity. The other possible explanation was offered by [42], namely that SCs are different from organizations and are more similar to the functional areas of an organization (for instance, marketing and accounting) in that they are focused on one task. Thus the successful use of BA may also be possible even if companies in the chain are more functionally-oriented.

The survey measured the BPO at the company level. It is quite possible that BPO is critical only in certain processes, depending on the focus of the company. The number of such processes varies and often it may be appropriate to link just one or a few of the key processes [45]. Thus, a general level of BPO may not have a strong moderating influence on the impact of BA on performance. Lastly, companies may use other ways to cooperate without necessarily increasing their BPO at least in the short term. For example, [54] proved that horizontal mechanisms, defined as structural overlays (such as roles and groups) and non-structural devices (such as physical co-location), can also improve collaboration and SC performance.

The results indicate that BPO may not be a necessary pre-condition for BA. These findings warrant further research to analyze whether the sequencing of an investment to first invest in an improvement of $\mathrm{BPO}$ and then BA is not the only possible way to obtain the benefits of BA use. It is possible that efforts to achieve a simultaneous improvement in both BPO and BA can bring a larger improvement in performance.

The investment in BA is a considerable undertaking for any organization; further gathering of enough data may be difficult and time consuming [20]. It is likely that a company is unable to make simultaneous efforts in each of the four SCOR areas: plan, source, make and deliver $[50,74]$. Our results provide a preliminary indication that an investment in BA in the Make area may bring the most significant improvement. Of course, the proper investment sequencing depends on the characteristics of a specific company/SC.

In terms of the information processing view the paper provides an advancement in the understanding of the various areas in SCM where information processing capabilities are important and provides a theoretical and empirical confirmation of the effect of these capabilities on performance. Further research is needed to identify the factors that influence the other side - namely information processing needs.

The paper has some limitations. The selection of companies in the sample may not be completely random since companies that were more aware of the importance of BA/process improvement might have been more inclined to participate. A refinement of the measurement of BA use in each of the four SCOR areas would also be beneficial. Further, the users' evaluation may not always accurately reflect the real quality of IS [29]. Finally, the impact of existing trust between companies in a chain has not been studied - without trust companies may not be prepared to share their data with others [76].

Future research could include case studies to acquire a more comprehensive view of how BA impact on various areas of performance. It should examine the potential differences in levels of $\mathrm{BPO}$ in different processes/organizational units of the same company and identify the processes where a high level of BPO may have a larger moderating influence. The moderating impact of a power relationship between companies in a SC on BA impact on performance should be analyzed.

Future research should also investigate whether the different kinds of IS (e.g. enterprise resource planning, web services/serviceoriented architecture) have a different moderating effect on the impact of BA in various areas of SCM on performance. Since performance was treated as a single construct in this paper, a much needed further investigation is how BA in various areas of SC impact different performance metrics, e.g. on-time delivery, quality, costs, reliability and flexibility. Closely connected is the question of the proper sequence of investing and the potentially different impact of $\mathrm{BA}$ in companies at different BPO levels.

A closely connected topic is an investigation of the development of performance measurement systems and the need for target analytical capabilities in specific areas. The development of analytic capabilities outside a focal company (in e.g. a customer-supplier dyad) could be studied to analyze how value is created in interorganizational networks. Finally, a longitudinal case study could be used to study the development of analytics capabilities over time; the analysis of the SC area on which a chain or a company at a certain maturity level should focus would be beneficial. It is possible that the required focus changes as a company's SC becomes more mature.

\section{Acknowledgments}

The authors would like to thank the two anonymous reviewers and Global BPM Team members for their several useful suggestions to improve earlier versions of the manuscript. 


\section{Appendix A. Questionnaire used in the survey.}

\section{Indicators of analytics capabilities in plan}

P1 Had you established supply chain performance measures?

P2 Doe you look at the impact of its strategies on supply chain performance measures?

P3 Do you use adequate analysis tools to examine the impact before a decision is made?

P4 Do you look at customer profitability?

P5 Do you look at product profitability?

P6 Do you analyze the variability of demand for your products?

P7 Do you use mathematical methods (statistics) for forecasting demand?

P8 Is a forecast developed for each product?

P9 Is a forecast developed for each customer?

P10 Does your demand management process make use of customer information?

P11 Is forecast accuracy measured?

Indicators of analytics capabilities in source

S1 Are the supplier inter-relationships (variability, metrics) understood and documented?

S2 Do you share planning and scheduling information with suppliers?

S3 Do you "collaborate" with your suppliers to develop a plan?

S4 Do you measure and feedback supplier performance?

Indicators of analytics capabilities in make

M1 Are your planning processes that are integrated and coordinated across divisions?

M2 Are supplier lead times updated monthly?

M3 Do you use constraint-based planning methodologies?

M4 Do you measure "adherence to plan"?

M5 Do the sales, manufacturing and distribution organizations collaborate in the planning and scheduling process?

M6 Is your customer's planning and scheduling information included in yours?

M7 Are plans developed at the "item" level of detail?

Indicators of analytics capabilities in delivery

D1 Do you track the percentage of completed customer orders delivered on time?

D2 Do you measure "out of stock" situations?

D3 Are the network inter-relationships (variability, metrics) understood and documented?

D4 Do you use a mathematical "tool" to assist in distribution planning?

D5 Are distribution management process measures in place?

D6 Are process measures used to recognize and reward the process participants?

Performance

P12 Overall, the Plan process area performs very well

S5 Overall, the Source process area performs very well

M8 Overall, the Make process area performs very well

D7 Overall, the Delivery process area performs very well

Indicators of information systems support

IS1 Does your information system currently support the supply chain processes?

IS2 Does your information system currently support the order commitment process?

IS3 Does your information system support distribution management?

IS4 Does your information system currently support the process (Make)?

IS5 Does your information system support this process (Source)?

IS6 Does your information system currently support the demand management process?

Indicators of a process orientation

PO1 Are your supply chain processes documented and defined?

PO2 Your chain organizational structure can be described as: (1-traditional function; 5-entirely process-based)

PO3 Your supply chain performance measures can be described as: (1-traditional function; 5-entirely process-based)

PO4 People in the supply chain organization can generally be described as: (1-internally-focused; 5-customer-focused)

PO5 Jobs in the supply chain can generally be described as: (1-"limited"-taskoriented; 5-"broad"-process-oriented)

\section{References}

[1] H. Aguinis, C.A. Pierce, Testing moderator variable hypotheses meta-analytically, Journal of Management 24 (5) (1998) 577-592.
[2] J. Auramo, J. Kauremaa, K. Tanskanen, Benefits of IT in supply chain management: an explorative study of progressive companies, International Journal of Physical Distribution \& Logistics Management 35 (2) (2005) 82-100.

[3] B. Azvine, D. Nauck, Z. Cui, Towards real-time business intelligence, BT Technology Journal 23 (3) (2005) 214-225.

[4] I. Bardhan, V. Krishnan, S. Lin, A Model to Measure the Business Value of Information Technology: the Case of Project and Information Work, Rady Schoo of Management, 2005.

[5] M. Barratt, Understanding the meaning of collaboration in the supply chain, Supply Chain Management - An International Journal 9 (1) (2004) 30-42.

[6] M. Benaroch, M. Jeffery, R. Kauffman, S. Shah, Option-based risk management: a field study of sequential IT investment decisions, Journal of Management Information Systems 24 (2) (2007) 103-140.

[7] P. Bolstorff, R. Rosenbaum, Supply Chain Excellence: a Handbook for Dramatic Improvement Using the SCOR Model, New York, Amacom, 2003.

[8] M. Borges, N. Hoppen, F.B. Luce, Information technology impact on market orientation in e-business, Journal of Business Research 62 (9) (2009) 883-890.

[9] R. Bose, Advanced analytics: opportunities and challenges, Industrial Management \& Data Systems 109 (2) (2009) 155-172.

[10] K. Burgess, P. Singh, R. Koroglu, Supply chain management: a structured literature review and implications for future research, International Journal of Operations \& Production Management 26 (7) (2006) 703-729.

[11] S. Cadez, C. Guilding, An exploratory investigation of an integrated contingency model of strategic management accounting, Accounting, Organizations and Society 33 (7-8) (2008) 836-863.

[12] J. Cai, X. Liu, Z. Xiao, J. Liu, Improving supply chain performance management: systematic approach to analyzing iterative KPI accomplishment, Decision Support Systems 46 (2) (2009) 512-521.

[13] N. Carr, IT doesn't matter, Harvard Business Review 81 (5) (2003) 41-49.

[14] B. Chae, H.R. Yen, C. Sheu, Information technology and supply chain collaboration: moderating effects of existing relationships between partners, IEEE Transactions on Engineering Management 52 (4) (2005) 440-448.

[15] H. Chen, D.D. Mattioda, P.J. Daugherty, Firm-wide integration and firm performance, The International Journal of Logistics Management 18 (1) (2007) $5-21$.

[16] J.J.-K. Cho, J. Ozment, H. Sink, Logistics capability, logistics outsourcing and firm performance in an e-commerce market, International Journal of Physical Distribution \& Logistics Management 38 (5) (2008) 336-359.

[17] B. Curtis, G.V. Seshagiri, D. Reifer, I. Hirmanpour, G. Keeni, The case for quantitative process management, IEEE Software 25 (3) (2008) 24-28.

[18] M. Dale Stoel, W.A. Muhanna, IT capabilities and firm performance: a contingency analysis of the role of industry and IT capability type, Information \& Managemen 46 (3) (2009) 181-189.

[19] T. Davenport, Competing on analytics, Harvard Business Review 84 (5) (2006) $150-151$.

[20] T. Davenport, Make better decisions, Harvard Business Review 87 (11) (2009) 117-123.

[21] B. Dehning, V.J. Richardson, R.W. Zmud, The financial performance effects of ITbased supply chain management systems in manufacturing firms, Journal of Operations Management 25 (4) (2007) 806-824.

[22] H. Demirkan, R.J. Kauffman, J.A. Vayghan, H.-G. Fill, D. Karagiannis, P.P. Maglio, Service-oriented technology and management: perspectives on research and practice for the coming decade, Electronic Commerce Research and Applications 7 (4) (2008) 356-376

[23] B. Dos Santos, Justifying investments in new information technologies, Management Information Systems 7 (4) (1991) 71-86.

[24] M.Z. Elbashir, P.A. Collier, M.J. Davern, Measuring the effects of business intelligence systems: the relationship between business process and organizational performance, International Journal of Accounting Information Systems 9 (3) (2008) 135-153.

[25] J. Emblemsvåg, Business analytics: getting behind the numbers, International Journal of Productivity and Performance Management 54 (1) (2005) 47-58.

[26] EncyclopaediaBritannica, Information system, 2010, http://www.britannica.com/ EBchecked/topic/287895/information-system.

[27] J.F. Fairbank, G.J. Labianca, H.K. Steensma, R. Metters, Information processing design choices, strategy, and risk management performance, Journal of Management Information Systems 23 (1) (2006) 293-319.

[28] D.G. Garson, Partial Least Squares regression (PLS), NC State University, 2009.

[29] D. Goodhue, R. Thompson, Task-technology fit and individual performance, MIS Quarterly 19 (2) (1995) 213-236.

[30] D.L. Goodhue, Understanding user evaluations of information systems, Management Science 41 (12) (1995) 1827-1844.

[31] A. Greasley, Using process mapping and business process simulation to support a process-based approach to change in a public sector organisation, Technovation 26 (1) (2006) 95-103.

[32] A. Groznik, A. Kovačič, P. Trkman, The role of business renovation and informatization in E-government, Journal of Computer Information Systems 49 (1) (2008) 80-88.

33] T. Gulledge, T. Chavusholu, Automating the construction of supply chain key performance indicators, Industrial Management \& Data Systems 108 (6) (2008) 750-774.

[34] D. Hedgebeth, Data-driven decision making for the enterprise: an overview of business intelligence applications, VINE 37 (4) (2007) 414-420.

[35] M.B. Heeley, R. Jacobson, The recency of technological inputs and financial performance, Strategic Management Journal 29 (7) (2008) 723-744.

[36] J.C. Henderson, N. Venkatraman, Strategic alignment: a model for organizational transformation through information technology, in: T. Kochan, M. Useem 
(Eds.), Transforming organizations, Oxford University Press, Oxford, 1992, pp. 97-117.

[37] M. Holweg, S. Disney, J. Holmström, J. Smaros, Supply chain collaboration: making sense of the strategy continuum, European Management Journal 23 (2) (2005) 170-181.

[38] R. Hoole, Five ways to simplify your supply chain, Supply Chain Management: An International Journal 10 (1) (2005) 3-6.

[39] I.P. Howell, P.W. Dorfman, S. Kerr, Moderator variables in leadership research, Academy of Management Review 11 (1) (1986) 88-102.

[40] C. Howson, Successful Business Intelligence: Secrets to Making BI a Killer App McGraw-Hill Osborne Media, 2008.

[41] S.H. Huan, S.K. Sheoran, G. Wang, A review and analysis of supply chain operations reference (SCOR) model, Supply Chain Management - An International Journal 9 (1) (2004) 23-29.

[42] G.T.M. Hult, D.J. Ketchen, S.F. Slater, Information processing, knowledge development and strategic supply chain performance, Academy of Management Journal 47 (2) (2004) 241-253.

[43] Z. Jourdan, K. Rainer, T. Marshall, Business intelligence: an analysis of the literature, Information Systems Management 25 (2) (2008) 121-131.

[44] R. Kohavi, N. Rothleder, E. Simoudis, Emerging trends in business analytics, Communications of the ACM 45 (8) (2002) 45-48.

[45] D.M. Lambert, M.C. Cooper, Issues in supply chain management, Industria Marketing Management 29 (1) (2000) 65-83.

[46] C.K.M. Lee, H.C.W. Lau, G.T.S. Ho, W. Ho, Design and development of agent-based procurement system to enhance business intelligence, Expert Systems with Applications 36 (1) (2009) 877-884.

[47] S. Li, B. Ragu-Nathan, T.S. Ragu-Nathan, S. Subba Rao, The impact of supply chain management practices on competitive advantage and organizational performance, Omega 34 (2) (2006) 107-124

[48] C. Liu, Q. Li, X. Zhao, Challenges and opportunities in collaborative business process management: overview of recent advances and introduction to the special issue, Information Systems Frontiers 11 (3) (2009) 201-209.

[49] A. Lockamy, K. McCormack, The development of a supply chain management process maturity model using the concepts of business process orientation Supply Chain Management: An International Journal 9 (4) (2004) 272-278.

[50] A. Lockamy, K. McCormack, Linking SCOR planning practices to supply chain performance: an exploratory study, International Journal of Operations \& Production Management 24 (12) (2004) 1192-1218.

[51] L. Mansar, H.A. Reijers, Best practices in business process redesign: use and impact, Business Process Management Journal 13 (2) (2007) 193-213.

[52] K. McCormack, Business Process Maturity: Theory and Application, BookSurge Publishing, Charleston, South Carolina, 2007.

[53] K. McCormack, W. Johnson, Business Process Orientation: Gaining the E-Business Competitive Advantage, St Lucie Press, Delray Beach, 2001.

[54] K. McCormack, A. Lockamy, The impact of horizontal mechanisms within sales and operations planning processes on supply chain integration and performance: a statistical study, 4th Global Conference on Business \& Economics, Oxford, UK, 2005.

[55] K. McCormack, W. Johnson, W. Walker, Supply Chain Networks and Business Process Orientation: Advanced Strategies and Best Practices, 2003.

[56] K. McCormack, J. Willems, J. Van den Bergh, D. Deschoolmeester, P. Willaert, M. Indihar Štemberger, R. Škrinjar, P. Trkman, M.B. Ladeira, M.P.V. de Oliveira, V. Bosilj Vuksić, N. Vlahović, A global investigation of key turning points in business process maturity, Business Process Management Journal 15 (5) (2009) 792-815.

[57] M.J. Meixell, V.B. Gargeya, Global supply chain design: a literature review and critique, Transportation Research Part E: Logistics and Transportation Review 41 (6) (2005) 531-550.

[58] S. Muylle, A. Basu, Online support for business processes by electronic intermediaries, Decision Support Systems 45 (4) (2008) 845-857.

[59] S. Negash, P. Gray, Business Intelligence, Springer, Berlin, Heidelberg, 2008

[60] A. Popovič, P.S. Coelho, J. Jaklič, The impact of business intelligence system maturity on information quality, Information Research 14 (4) (2009) paper 417.

[61] K. Pramatari, Collaborative supply chain practices and evolving technological approaches, Supply Chain Management - An International Journal 12 (3) (2007) 210-220.

[62] T.S. Raghu, A. Vinze, A business process context for Knowledge Management, Decision Support Systems 43 (3) (2007) 1062-1079.

[63] J. Ranjan, Business justification with business intelligence, VINE: The journal of information and knowledge management systems 38 (4) (2008) 461-475.

[64] T. Ravinchandran, C. Lertwongsatien, Effect of information systems resources and capabilities on firm performance: a resource-based perspective, Journal of Management Information Systems 21 (4) (2005) 237-276.

[65] P.M. Reyes, Logistics networks: a game theory application for solving the transshipment problem, Applied Mathematics and Computation 168 (2) (2005) 1419-1431.

[66] C.M. Ringle, S. Wende, and A. Will, The finite mixture partial least squares approach: methodology and application. (Berlin et al., 2007).

[67] B. Ritchie, C. Brindley, Supply chain risk management and performance: a guiding framework for future development, International Journal of Operations \& Production Management 27 (3) (2007) 303-322.

[68] B.S. Sahay, J. Ranjan, Real time business intelligence in supply chain analytics, Information Management \& Computer Security 16 (1) (2008) 28-48.
[69] J. Schiefer, A. Seufert, Management and controlling of time-sensitive business processes with sense, computational intelligence for modelling, Control and Automation (2005) 77-82.

[70] J. Shang, P.R. Tadikamalla, L.J. Kirsch, L. Brown, A decision support system for managing inventory at GlaxoSmithKline, Decision Support Systems 46 (1) (2008) $1-13$.

[71] J.F. Shapiro, Challenges of strategic supply chain planning and modeling, Computers and Chemical Engineering 28 (6-7) (2004) 855-861.

[72] M. Song, W.M.P. van der Aalst, Towards comprehensive support for organizational mining, Decision Support Systems 46 (1) (2008) 300-317.

[73] H. Stadtler, Supply chain management and advanced planning-basics, overview and challenges, European Journal of Operational Research 163 (3) (2005) 575-588.

[74] G. Stewart, Supply-chain operations reference model (SCOR): the first crossindustry framework for integrated supply-chain management, Logistics Information Management 10 (2) (1997) 62-67.

[75] M. Tenenhaus, V.E. Vinzi, Y.-M. Chatelin, C. Lauro, PLS path modeling, Computational Statistics \& Data Analysis 48 (1) (2005) 159-205.

[76] S. Terzi, S. Cavalieri, Simulation in the supply chain context: a survey, Computers in Industry 53 (1) (2004) 3-16.

[77] P. Trkman, The critical success factors of business process management, international journal of information management, (2009) In press.

[78] P. Trkman, K. McCormack, A conceptual model for managing supply chain risk in turbulent environment, International Journal of Production Economics 119 (2) (2009) 247-258.

[79] P. Trkman, M. Indihar Štemberger, J. Jaklič, A. Groznik, Process approach to supply chain integration, Supply Chain Management - An International Journal 12 (2) (2007) 116-128.

[80] P. Valente, G. Mitra, The evolution of web-based optimisation: from ASP to eServices, Decision Support Systems 43 (4) (2007) 1096-1116.

[81] W.M.P. van der Aalst, H.A. Reijers, A.J.M.M. Weijters, B.F. van Dongen, A.K. Alves de Medeiros, M. Song, H.M.W. Verbeek, Business process mining: an industrial application, Information Systems 32 (5) (2007) 713-732.

[82] H.J. Watson, B.H. Wixom, J.A. Hoffer, R. Anderson-Lehman, A.M. Reynolds, Realtime business intelligence: best practices at continental airlines, Information Systems Management 23 (1) (2006) 7-18.

[83] S. Williams, N. Williams, The Profit Impact of Business Intelligence, Morgan Kaufmann, San Francisco, 2007.

[84] B.H. Wixom, H.J. Watson, A.M. Reynolds, J.A. Hoffer, Continental Airlines Continues to Soar with Business Intelligence, Information Systems Management 25 (2) (2008) 102-112.

[85] H. Zhou, J.W.C. Benton, Supply chain practice and information sharing, Journal of Operations Management 25 (6) (2007) 1348-1365.

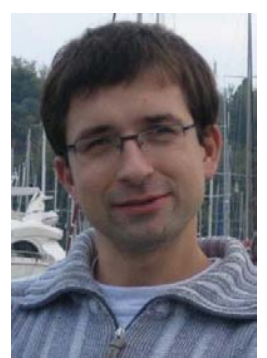

Dr. Peter Trkman is an assistant professor at the Faculty of Economics of the University of Ljubljana. His research and teaching interests encompass technology adoption, e-government and various aspects of the supply chain, business process and operations management. He has participated in several national and international projects (both research and consulting) and published over 60 papers/book chapters, including papers in Computers \& Operations Research, European Journal of Operational Research, Government Information Quarterly, IEEE Transactions on Engineering Management, International Journal of Information Management, International Journal of Production Economics, International Journal of Production Research, Online Information Review, Supply Chain Management - An International Journal, Technology Forecasting \& Social Change and Telecommunications Policy.

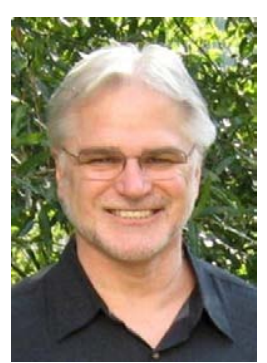

Dr. McCormack is currently President of DRK Research, a global business analytics research network and a SAS partner. He is also associated with several Universities such as Babson College, NC State, and the University of Oklahoma and is the Master Instructor for Supply Chain Risk with the Supply Chain Council. He has over 30 years of business leadership, engineering, teaching, research and consulting experience in the areas of information technology, operations management, and supply chain management. Dr. McCormack is also a judge for the Manufacturer of the Year award for the state of Alabama. Some of his clients have been Chrysler, Daimler, Texas Instruments, USMC, USAF, Chevron-Phillips, Shell, Exxon-Mobil, Dow Chemical, Standard Charter Bank, Microsoft, Intel, several state governments, Wal-Mart, Campbell's Soup, General Mills, and PepsiCo.

Dr. McCormack has degrees in Chemistry, Engineering, an MBA and a DBA. He has also developed and delivered courses in Information Technology, HR, Operations Management, and Supply Chain Management at the graduate and undergraduate level both in the U.S., China and Europe. He has published five books and over 100 articles in Quality Progress, Business Process Management Journal, Supply Chain Management, Benchmarking: An International Journal, Supply Chain Management Review and several others. 


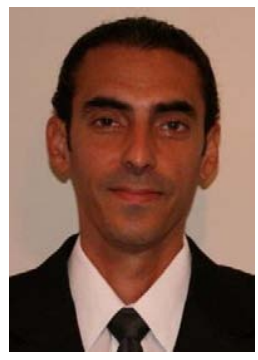

A native of Brazil, Marcos graduated in Business Administration from the Universidade Federal de Minas Gerais and worked as an Information Technology Manager for almost 15 years when he had a chance to participate in several projects including software development, warehouse systems project, and logistical related activities. Marcos also took CMM courses at Software Engineering Institute and participated for almost 3 years as a PMI/ OPM3 team member. Now he holds a Project Manager position at NIPE-Log/UFMG (Interdisciplinary Center for Logistics Research at UFMG). Marcos has taught Logistics and Supply Chain Management courses at both the undergraduate and graduate levels in Brazil, the list of Business School where he teaches includes Fundação Dom Cabral, Pontifícia Universidade Católica and Universidade Federal de Minas Gerais. He holds a MsC and is a PhD Candidate in Logistics and Supply Chain Management from the Universidade Federal de Minas Gerais. Marcos has published several local and international books, periodicals and congresses like Supply Chain Management: An International Journal, IPSERA, EUROMA, POMS. His current research interests include the supply chain maturity models, supply chain risk management, logistical performance and logistical networks.

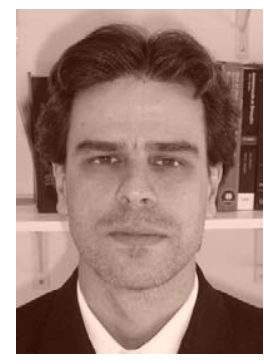

Marcelo Bronzo is an associate professor at the Universidade Federal de Minas Gerais (UFMG), Brazil. He holds an $\mathrm{MsC}$ and $\mathrm{ahD}$ in Logistics and Supply Chain Management from Cepead-UFMG. His main and current research interests are focused on logistics and operations performance; process management; best practices on supply processes in auto industry and investigations on supply chain management processes maturity. He has attended and presented several works on international congresses such as IPSERA, POMS and EUROMA, and published articles in international periodicals, including papers on the Business Process Management Journal and Supply Chain Management: An International Journal. 